\title{
Sintering of Pellets, Compound by Fly Ash, Clay and Charcoal in a Fixed Bed Combustion Reactor
}

\author{
Alvino Oliveira Melo ${ }^{1}$, Emanuel Negrão Macêdo ${ }^{2}$, Danielly Quaresma², José Antônio da S. Souza ${ }^{2}$, Alacid Neves ${ }^{2}$ \\ and Márcio Ferreira Martins ${ }^{3}$ \\ 1. Department of Mechanical and Materials, Federal Institute of Education, Science and Technology of Maranhão, S. Luís-Ma \\ 65030-005, Brazil \\ 2. Department of Chemical Engineering, Federal University of Pará, Belém, PA 66075-110, Brazil \\ 3. Laboratory of Combustion and Combustible Matter (LCCm), Federal University of Espirito Santo, Vitoria-ES 29075-910, Brazil
}

\begin{abstract}
Normally, industries in general, produce waste at its majority toxic, such as fly ash, for example, which damage the environment. The aim of this paper is to investigate the evolution of the temperature in a combustion reactor, full of pellets manufactured with fly ash, clay and charcoal powder, after sintering, to obtainment synthetic aggregates for use in civil construction. The pellets were produced in a cement mix. For realization of the work, a co-current combustion reactor was made in order to analyze the temperatures profile and investigate if the values of these temperatures would be sufficient to initiate the process of sintering of the pellets. Temperatures reached in the reactor varied in the range of $800{ }^{\circ} \mathrm{C}-1,290{ }^{\circ} \mathrm{C}$. These values are sufficient to initiate the process of sintering of the pellets. For the experiment realized, parameters such as inlet velocity of the fluid (air), diameters of the pellets and size of charcoal crushed in a disk mill were varied and the effect of variations of these parameters were analyzed for the experiment. The historical temperatures were recorded by a data acquisition instrument and subsequently plotted for analysis.
\end{abstract}

Key words: Combustion reactor, charcoal, fly ash, clay, porous media.

\section{Introduction}

Porous medium is a material that consists of a solid matrix with interconnected voids. Suppose that the solid matrix is either rigid, the usual situation, or it undergoes small deformation. The interconnectedness of the voids or pores allows the flow of one or more fluids through the material. As examples, natural porous media can cite beach sand, sandstone, limestone, wood, and the human lung [1].

Several experimental and theoretical studies of the combustion of coal or wood particles in a fixed bed have been conducted in order to understand the phenomena that occur during the combustion process in porous media such as heat and mass transfer. However, the parameters that govern the combustion

Corresponding author: Alvino Oliveira Melo, professor, D. Eng., research fields: combustion process and industry residues recycling. of solids in the bed, such as the effects of particle size, heat and mass transfer in porous media, and the interference between the solids reactions and gas phase, are not fully understood [2]. To understand these processes of complex interpretations, a combustion reactor was developed and filled with a porous solid material, pellets, predominantly spherical in geometric shape, consisting of a mixture previously defined with a percentage fly ash of clay, and charcoal.

The fuel used in the combustion reaction was charcoal, crushed in a disc mill in order to control the grain size. In this work parameters such as the rate of supply of air, the influence of the size of the fuel particles (charcoal) and of the pellets (fly ash, charcoal and clay powder) were studied during the combustion reaction.

Fly ash contains trace amounts of toxic metals (U, 
Th, Cr, Pb, Hg, Cd etc.), which may have negative effect on human health and on plants [3].

Charcoal is a highly porous material. The porosity of charcoal is about $90 \%$, and this value can vary depending on the type or origin of the wood [4]. The granulometry of the charcoal with contents of fixed carbon and the porosity are main factors that affect the reactivity. The reactivity can be defined as the speed at which, at a given temperature, the carbon reacts with a gas containing oxygen.

Clays are essentially constituted in its composition by silicon, aluminum, water, iron, alkali metals and alkaline-earth. The clays generally contain 28 organic matter, soluble salts, quartz particles, pyrite, mica, calcite, dolomite and other residue of minerals non-crystalline [5]. Clay is as a naturally occurring material composed primarily of mineral of low granulometry, which has plasticity at appropriate water contents [6].

The combustion reaction is initiated by a chemical reaction between fuel and oxygen for the purpose of heat generation. As a result of the combustion reaction, chemicals such as $\mathrm{SO}_{2}$ and $\mathrm{SO}_{3}$ are produced. The $\mathrm{CO}_{2}$ results from complete combustion while the $\mathrm{CO}$ results from incomplete reaction during the combustion reaction. Industrially objective is to produce a maximum amount of heat during the combustion process. During the combustion process, the carbon reacts with oxygen on the surface to form carbon monoxide and carbon dioxide, but generally, carbon monoxide is the main product [4], as shown in Eq. (1):

$$
\mathrm{C}+\frac{1}{2} \mathrm{O}_{2} \rightarrow \mathrm{CO}
$$

The carbon surface also reacts with carbon dioxide and water vapor as show the reduction equations:

$$
\begin{gathered}
\mathrm{C}+\mathrm{CO}_{2} \rightarrow 2 \mathrm{CO} \\
\mathrm{C}+\mathrm{H}_{2} \mathrm{O} \rightarrow \mathrm{CO}+\mathrm{H}_{2}
\end{gathered}
$$

The reduction Eqs. (2) and (3) are usually slower than the oxidation reaction (1), and generally for the combustion only reaction (1) needs to be considered.
During the reaction, the smoldering combustion was predominantly, where the smoldering is a fundamental combustion problem involving heterogeneous chemical reactions and the transport of heat, mass and momentum in the gas and solid phases. The fundamental difference between smoldering and flaming combustion is that, in the former, the oxidation reaction and the heat release occur on the solid surface of the fuel or porous matrix and, in the latter, these occur in the gas phase surrounding the fuel [7]. Data acquisition was taken by "Paper-Less Recorder PHL" properly attached to the thermocouples axially distributed throughout the combustion reactor. Nine experiments were performed. The experiments 1 , 2, 3, 4 and 5 were discarded due the problems presented during the evolution of the combustion reaction throughout the bed. In this paper, the front reaction combustion analysis is realized for experiment 8, once that alls experiments studied present a similar characteristic in combustion regime. The velocity combustion analysis takes in consideration the experiments 6, 7, 8, and 9. Temperature profile analysis in reactor also is considered the experiment 8.

\section{Description of the Experiment}

The experiment consists of a fixed bed reactor shown in Fig. 1a, it is based in a work developed in the Université de Tolouse [8]. The fixed bed reactor is a cylinder made of carbon steel with a thickness of 1/8" with 158 mm internal diameter, 700 mm height and $164 \mathrm{~mm}$ of external diameter shown in Fig. 1b. For getting one-dimensional propagation of the combustion front, walls of the reactor are insulated by an insulation layer of rock wool fiber with $30 \mathrm{~mm}$ thickness. By means of this insulation radial losses are minimized and propagation on the reactor axis can be considered one-dimensional. Seven type $K$ thermocouples are distributed throughout the reactor, keeping appropriate distances shown in Figs.1a and 1b. Fig.1b shows the reactor scheme. The data taken by "Paper-Less Recorder PHL” shown in Fig. 1c, were plotted and analyzed. 


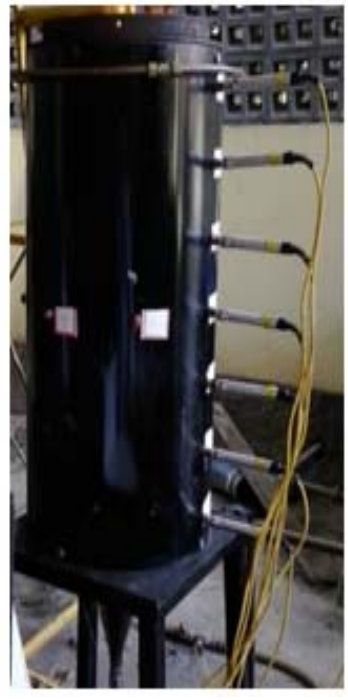

(a)

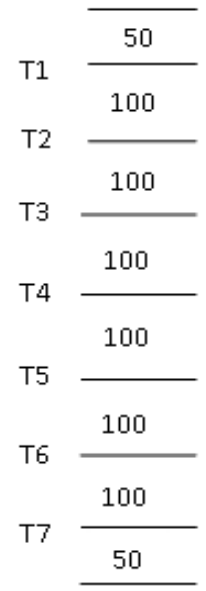

(b)

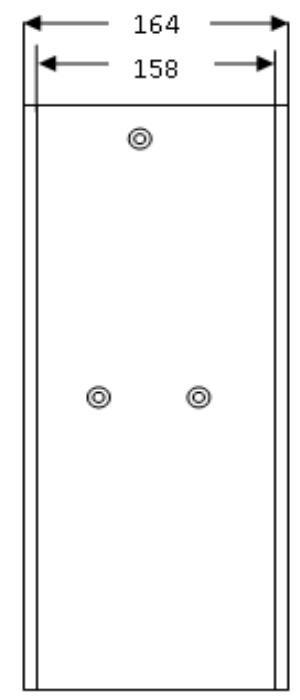

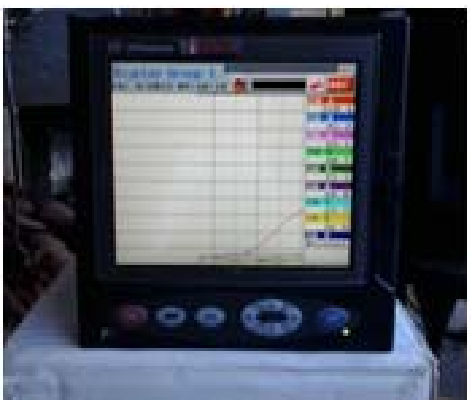

(c)

Fig. 1 (a) Combustion reactor in situ; (b) reactor schematic draw; and (c) paper-less recorder.

\section{Experimental Set Up}

The experimental set up shown in Fig. 2, it is composed by: 1-combustion cell; 2-cone; 3-acrylic tube; 4 and 5-control valves; 6-exhaust; 7-air collector; 8-air exhaust; 9-thermocouples; 10-manometer; 11-burner; 12 -cover; 13-centrifugal fan; 14-crown. Air is initially introduced into the combustion reactor by means of a exhaust (6) connected to the reactor outlet for a $1 / 2$ inch copper tubing. A perforated grate ensures a distribution of air flow, beyond to avoid efficiently the reactor obstruction with ashes suctioned by the exhaust. The air flow rates are controlled by manual valves (4) and (5), the velocity of air flows are measured for each experiment through a anemometer with the reactor previously filled with the pellets, before start the combustion. A centrifugal fan (13) was used to cool the gas temperature at the reactor exit. Seven thermocouples are placed inside the reactor such that their extremity is located on the center line of the combustion reactor axis as shown in Figs. 1a and 1b. A thermocouple placed on the outside surface of the reactor was used to measure the temperature of the reactor at that location, and in accordance with the temperature recorded by the data logger, it was observed that the temperature at the outer surface is approximately $9 \%$ of the internal temperature, showing this way that the heat flow along the bed can be considered one-dimensional.

\section{Experimental Procedure}

\subsection{Pellets Production Procedures}

The production of the pellets are described in the six steps following: (1) Drying the coal and clay in a electric kiln at a temperature of $105{ }^{\circ} \mathrm{C}$; (2) Crushing the coal in a disc mill; (3) Grind coal and clay for 30 min in a ball mill; (4) Homogenization of the coal, clay and fly ash in the ball mill during one hour; (5) Production of aggregates in a cement mixer; (6) The aggregates (pellets) produced were removed from mixer and heated in a electric kiln at $105{ }^{\circ} \mathrm{C}$ for a period of $24 \mathrm{~h}$. The pellets were manufactured with $30 \%$ fly ash, $40 \%$ clay, and 30\% charcoal powder.

After performing several experiments, it was concluded that for each $1 \mathrm{~kg}$ of aggregates would be ideal to use approximately $400 \mathrm{~mL}$ of water, obtaining in this way an aggregate (pellets) that after drying in an electric kiln, becomes resistant enough to be used in the combustion reactor, during the experiment. 


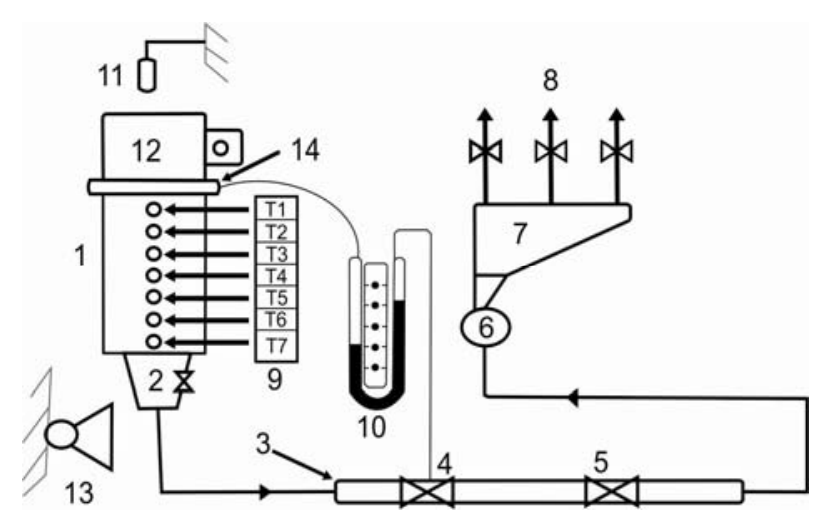

Fig. 2 Combustion process set up.

\subsection{Combustion Reaction Procedure}

The fixed bed reactor was filled with $80 \%$ of coal milled with size suitably selected with sieves and $20 \%$ pellets until a height of $700 \mathrm{~mm}$ (completely filled). The fuel (coal milled) was slightly compressed and the procedure was adopted for the different tests. The ignition of the solid fuel (coal milled) begins with an external flame of a burner, using butane gas as fuel, uniformly distributed across the surface of the fuel as shown in Fig. 3, to make the process homogeneous. After completing the process of ignition, start the self sustenance of the flame propagation. The time for ignition of the fuel and the self sustenance flame was about 6 min when the thermocouple 1, placed at a distance of $50 \mathrm{~mm}$ from the top of the reactor, accused a temperature of approximately $700{ }^{\circ} \mathrm{C}$, then cut the fuel (butane gas) to the burner and the combustion reaction progressed self sustained. The burner was placed at a distance of about $13 \mathrm{~mm}$ from the top of the reactor (Fig. 3).

The process variables are the velocity of the oxidant forced flow, the diameter of the pellets and the coal particle size. Temperatures are recorded as a function of time by the seven thermocouples distributed axially along the reactor and properly connected to the data logger (paperless recorder). The propagation of the reaction front is determined by the time taken for the reaction cross two consecutive thermocouples. The arrival of the reaction front in a thermocouple is determined by a sudden increase in temperature. Only

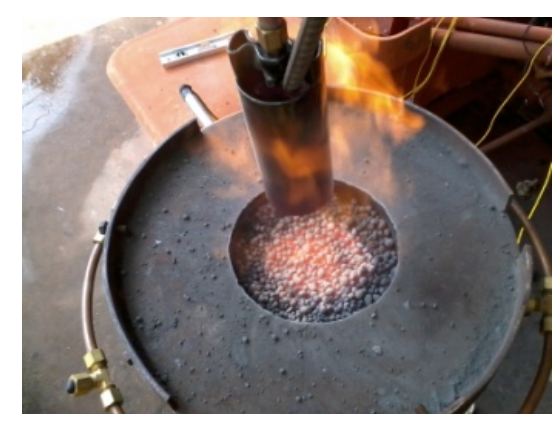

Fig. 3 Combustion Ignition of the solid fuel.

thermocouples placed in the center line of the fuel bed is used to calculate the speed of propagation of the flame front [9].

\section{Pellets Elemental Chemical Analysis}

5.1 Analysis of Pellets before Combustion in the Reactor

Table 1 shows the elemental chemical analysis of the pellets before combustion. And it also shows the predominance of carbon before combustion of the pellets in the reactor.

\subsection{Analysis of Pellets after Combustion in the Reactor}

Table 2 shows the elemental chemical analysis of the pellets after combustion. And it also shows that after the combustion process, the carbon in the pellets went fully consumed, remainder proportion of oxygen, aluminum, silicon, calcium and iron.

\section{Thermo Gravimetric Analysis}

Thermo gravimetric analysis of the samples was performed taking in consideration the mass loss of the sample during the combustion reaction. Fig. 4 shows that dry of the sample is performed until a temperature approximately $50{ }^{\circ} \mathrm{C}$. Between temperatures (50-350 ${ }^{\circ} \mathrm{C}$ ) it observes a very small quantity of mass consumed, indicating that in this temperature range the pellets react slowly in the combustion reaction, showing that in this range the pellets absorb heat in the reaction which is a characteristic phenomenon of an endothermic reaction. 
Table 1 Chemical composition of the pellets before the combustion.

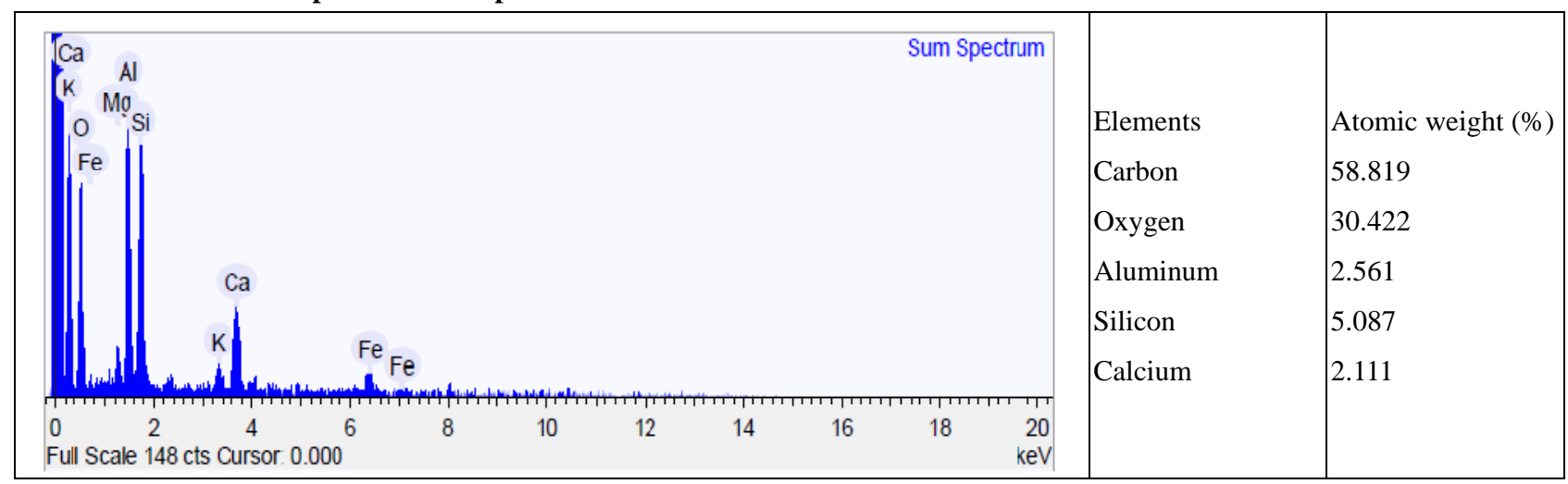

Table 2 Chemical composition of the pellets after combustion.

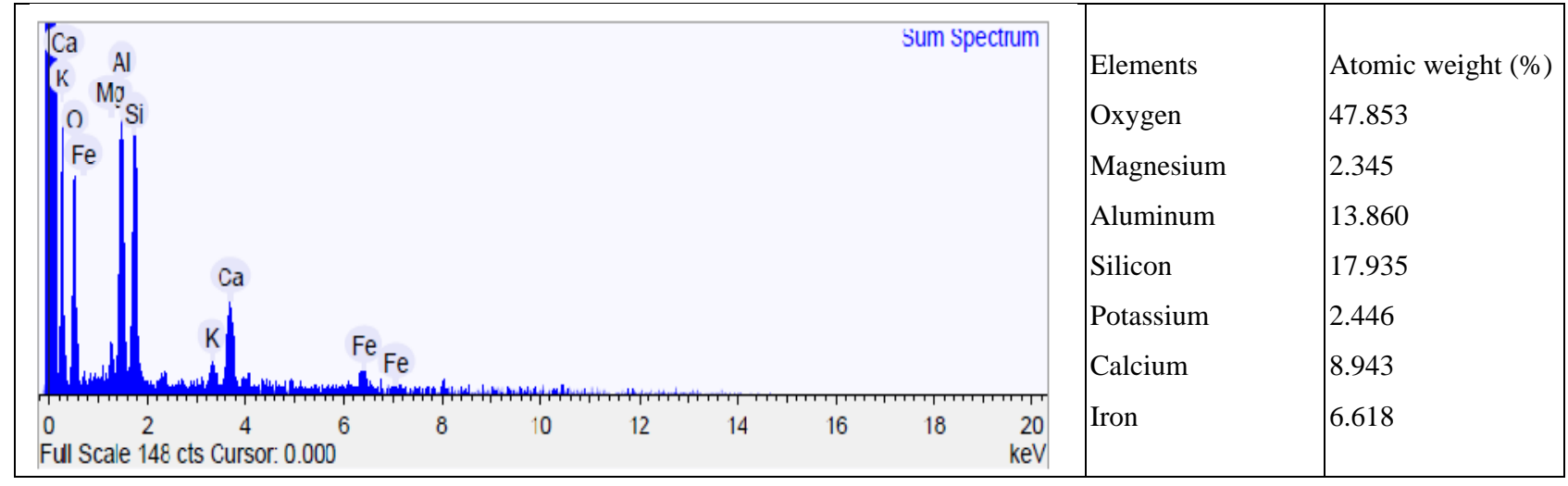

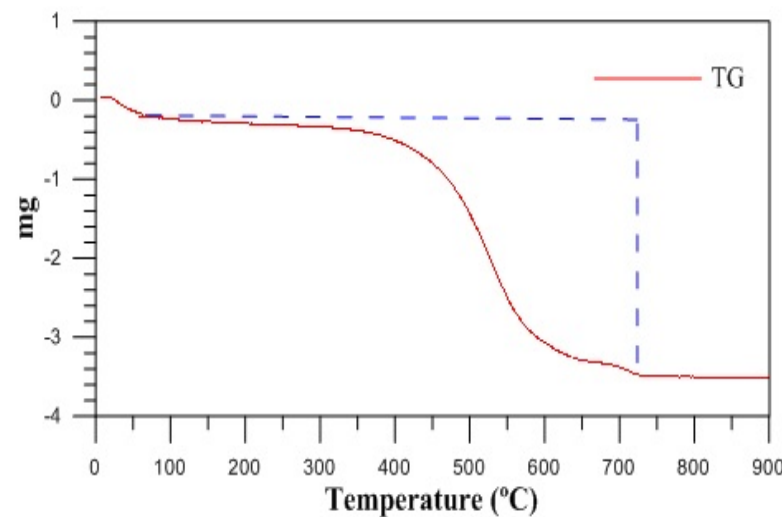

Fig. 4 Thermal analysis of the pellets in an atmosphere of synthetic air.

The major mass loss occurs in the temperature range of about $\left(350-750{ }^{\circ} \mathrm{C}\right)$, because in this range the pellets have absorbed sufficient heat to start a more intense combustion and in consequence mass consumption is accelerated. Between range (750-900 ${ }^{\circ} \mathrm{C}$ ), the quantity of matter remains constantly, indicating the end of the reaction. Fig. 4 shows that at the end of the combustion process, approximately $85 \%$ of matter were consumed during the combustion. After end of the combustion, it is expected the combustion reactor be cold, then is removed all material that after combustion has undergone a sintering process, as illustrated in Fig. 5.

\section{Experiment Results Performed in Combustion Reactor}

\subsection{Combustion Front Analysis}

The result of the experiment shown in Fig. 6, was

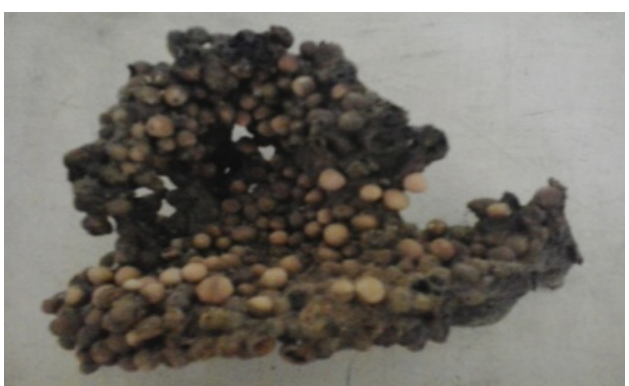

Fig. 5 Aspect of pellets after sintering process during the combustion reaction. 


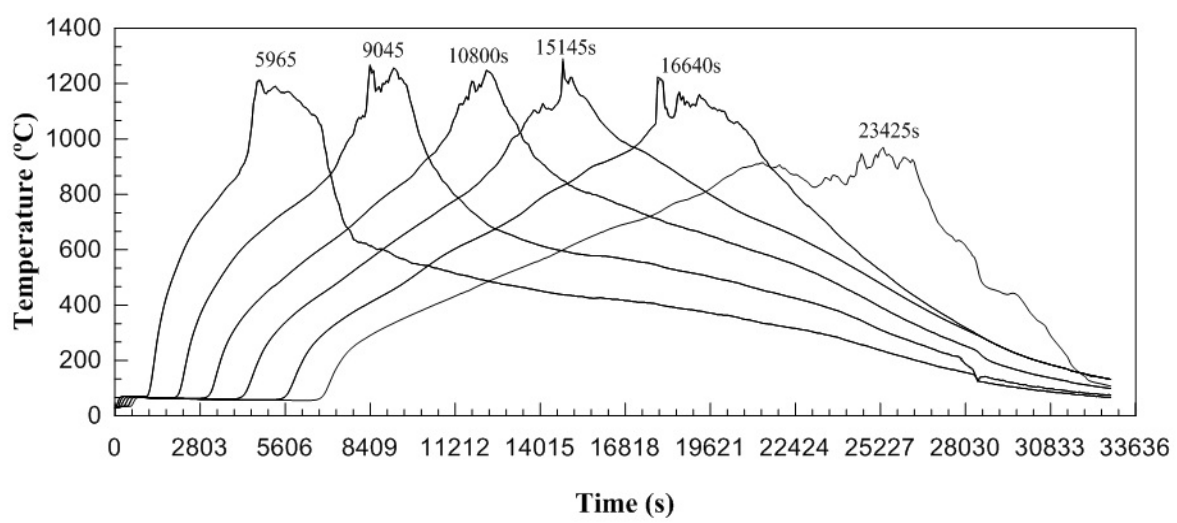

Fig. 6 Evolution of the combustion front.

conducted with air flow velocity of $0.63 \mathrm{~m} / \mathrm{s}$, the pellet diameters varying between $5.66 \mathrm{~mm}-9.62 \mathrm{~mm}$, the charcoal granulometry ranging between $3.36 \mathrm{~mm}-5.66$ $\mathrm{mm}$, mass of the pellets in the reactor $1.64 \mathrm{Kg}(20 \%$ of the bed), charcoal mass in the reactor $2.51 \mathrm{Kg}(80 \%$ of bed), total mass in the reactor $4.15 \mathrm{Kg}$. The passage of the front of ignition is determined by historical temperatures [5]. At a temperature of approximately $50{ }^{\circ} \mathrm{C}$, it is completely removed $3.5 \%$ of moisture of the pellets. The fuel temperature remains substantially constant at the point where temperature reaches a maximum value, approximately $1,290{ }^{\circ} \mathrm{C}$, perhaps due a uniform distribution diameter pellets.

Except the thermocouple 7, it is observed that there is a discrepancy of temperatures results shown in Fig. 6. The accumulation of materials on the bottom of the combustionn reactor and over the thermocouple sensor could act as a thermal insulator keeping the temperature around $900{ }^{\circ} \mathrm{C}$ during about $6,000 \mathrm{~s}$, then the temperature begins to fall.

There was a consumption of approximately $76 \%$ of the total mass of fuel that reacted within the bed. It is observed that near of the maximum temperature region it has an instability of the temperature. This instability can be attributed to the effect of accommodating of the fuel pellets while the charcoal is consumed. From the maximum temperature point where there was an accommodation of the fuel, the structure of the bed becomes more stable and the temperature evolution becomes smoother. After completion of the reaction the temperature decreases rapidly, showing that there is little heat generation after the forward reaction has been completed. The maximum temperature remains practically constant throughout the bed and decreases significantly only when the forward reaction consumes the whole fuel.

\subsection{Fluid Flows Velocity Analysis}

The data present in Fig. 7, correspond to an initial air temperature of $27^{\circ} \mathrm{C}$, charcoal crushed is used as fuel. The air flow velocity for experiments is shown in the figure. It is important notes that the velocity propagation is not constant throughout the reactor [9]. The experiments 6 and 8 show similar velocity profiles, possibly for these experiments, there was a similar uniform distribution of charcoal and pellets. It is also observed that the propagation velocity of the experiments 6, 8 and 9 increase in reactor outlet because the air is sucked from the bottom of the reactor through an exhaust. Exception is observed for the experiment 7 , where the front propagation velocity reduces at the exit of the combustion reactor, possibly due to obstruction of the bed by pellets that are too concentrated in the bottom of the reactor for this experiment.

Based on the above analysis, it can be concluded that the uniform distribution of charcoal and the pellets inside the reactor is required for that the flow velocity of the reaction front advance smoothly without presenting many high peaks within the bed. 
Fig. 7 shows either that the front propagation velocity decreases with increasing of air flow, this confirms the theory that the fuel system is dominated by the reaction of heat transfer to the fuel that enters and the oxidant [9].

\subsection{Temperature Profile Analysis in Reactor}

To determine the axial temperature profile across the combustion reactor is first generated the graph temperatures verses time, Fig. 8. For a given thermocouple, keeping the time constant, as indicated by the arrows in bold, find the values of the temperatures to the other thermocouples. Through Excel resources, generates Table 3 , where $\mathrm{Z}$ is the axial direction of the reactor measured in millimeters and temperatures are given in ${ }^{\circ} \mathrm{C}$. With the results obtained, the axial temperature profile along the reactor is plotted and analyzed as illustrated in Fig. 9.

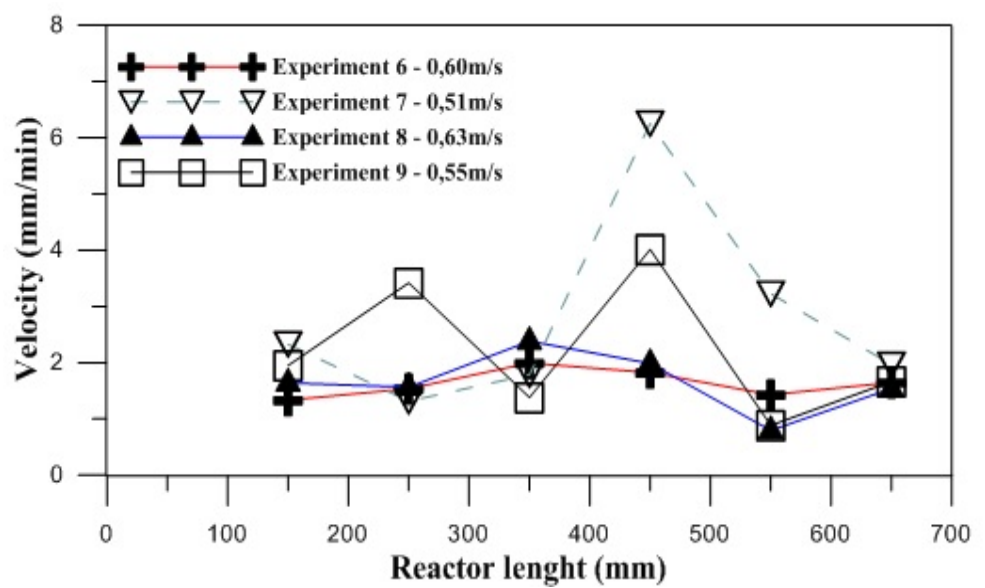

Fig. 7 Propagation velocity across the combustion cell.

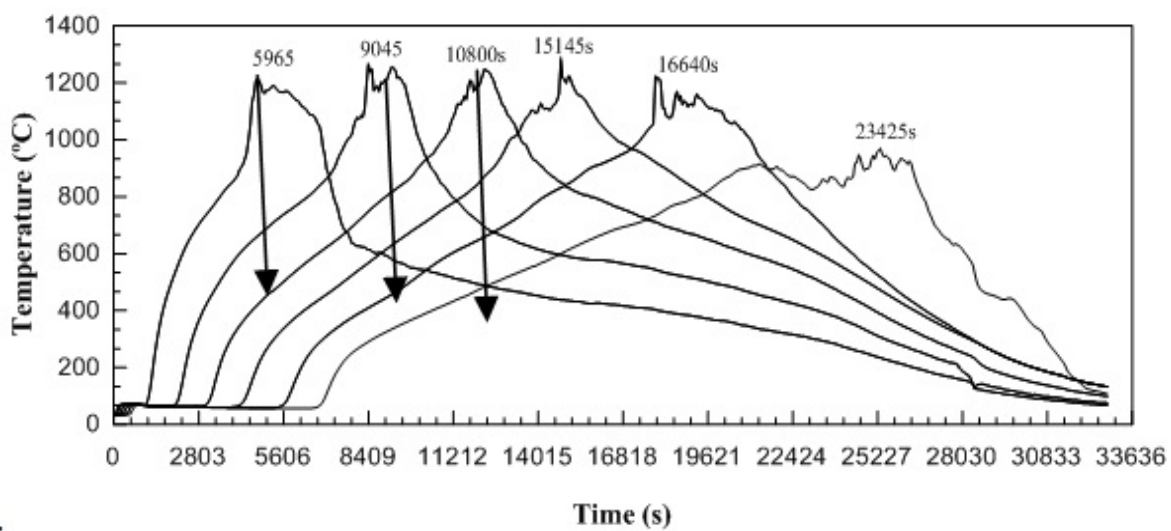

Fig. 8 Evolution of the axial temperature in the reactor.

Table 3 Data for generating the axial profile temperature across combustion reactor.

\begin{tabular}{llllll}
\hline $\mathrm{Z}(\mathrm{mm})$ & $\begin{array}{l}\mathrm{T} 2 \\
\left({ }^{\circ} \mathrm{C}\right)\end{array}$ & $\begin{array}{l}\mathrm{T} 3 \\
\left({ }^{\circ} \mathrm{C}\right)\end{array}$ & $\begin{array}{l}\mathrm{T} 4 \\
\left({ }^{\circ} \mathrm{C}\right)\end{array}$ & $\begin{array}{l}\mathrm{T} 5 \\
\left({ }^{\circ} \mathrm{C}\right)\end{array}$ & $\begin{array}{l}\mathrm{T} 6 \\
\left({ }^{\circ} \mathrm{C}\right)\end{array}$ \\
\hline 50 & 495.2 & 412.1 & 330.9 & 308.6 & 282.4 \\
150 & $1,217.6$ & 617.2 & 488 & 438.9 & 401 \\
250 & 664 & $1,283.5$ & 698.2 & 597.5 & 543 \\
350 & 425 & 754.8 & $1,248.3$ & 851.8 & 711 \\
450 & 212.6 & 570.6 & 868 & $1,296.2$ & 920.3 \\
550 & 58.5 & 293.4 & 659.1 & 831.2 & $1,264.3$ \\
650 & 58.1 & 291.9 & 482.6 & 599.1 & 882.2 \\
\hline
\end{tabular}




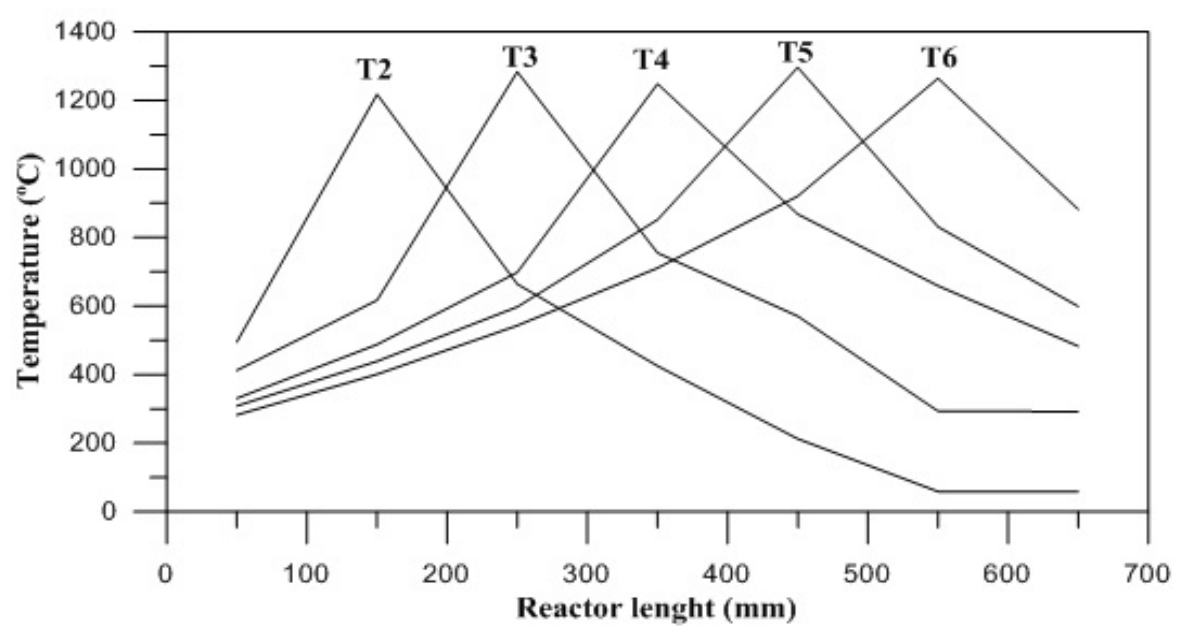

Fig. 9 Temperature profile across the reactor.

Fig. 9 shows that the maximum temperatures of the reaction front in the place where the thermocouples are positioned, presents uniform values around $1,290{ }^{\circ} \mathrm{C}$, which is a temperature sufficient to sinter the pellets. Fig. 5 shows the material pellets after the end of combustion.

\section{Conclusions}

During realization of the experiment, the fuel temperature remains almost constant at the point where temperature reaches a maximum value, approximately $1,290{ }^{\circ} \mathrm{C}$, sufficient temperature for sintering the aggregates. It was observed to the experiment, the evolution of the combustion reaction front in the fixed bed, what turns possibly the use of this technology for recycling industry residue, as fly ash, from industries. The use of the final product continues being investigated by Department of Chemical Engineering of the Federal University of Pará-Brazil. Preliminary studies show that fly ash can be used in the production of synthetic aggregate. Investigation of the use of the final product, after the combustion reaction, is also being discussed as elements which contribute to the atmosphere carbon sequestration and in application as adsorbents.

\section{Acknowledgments}

The authors are sincerely thankful to CAPES, FAPEMA, IFMA and PRODERNA-UFPA for their respective research support.

\section{References}

[1] Donald, A., and Adrian, N. B. 2013. Convection in Porous Media. Fourth Edition. New York: Springer.

[2] Kaviany, M. 1995. Principles of Heat Transfer in Porous Media. Second Edition. New York: Springer-Verlag New York, Inc.

[3] Dhadse, S., Kumari, P., and Bhagia, L. J. 2008. "Fly Ash Characterization, Utilization and Government Initiatives in Indian-A Review.” Journal of Scientific \& Industrial Research 67: 11-8.

[4] Borman, G. L., and Ragland, K. W. 1998. Combustion Engineering. WCB/Mc Graw Hill.

[5] Miller, G. T., and Spoolman, S. 2009. Living in the Environment: Principles, Connections and Solutions. $16^{\mathrm{a}}$ ed. Belmont: Brooks/Cole, 353.

[6] Guggenheim, S., and Martin, R. T. 1996. "Comment on Definition of Clay and Clay Mineral: Joint Report of the AIPEA Nomenclature and CMS Nomenclature Committees.” Clays and Clay Minerals 44: 710-2.

[7] Rein, G. 2009. "Smoldering Combustion Phenomena in Science and Technology." International Review of Chemical Engineering 1: 3-18.

[8] Martins, M. F. 2008. “The Structure of a Combustion Front Propagating in a Fixed Bed of Crushed Oil Shale: Co-current Configuration.” Ph.D. thesis, L’ Université de Toulouse.

[9] Zou, X., Torero, J. L., Goudeau, J. C., and Bregon, B. 1995. "On the Propagation of a Reaction Front through a Porous Fuel in the Presence of an Opposed Forced Flow: Application to Mixtures Characteristic of Municipal Waste.” Université de Poitiers-UPR. Comb. Sci. and Tech 10-111: 123-46. 